\title{
DESIGN AND ANALYSIS OF AIR FLOW DEPRESSION FOR AIR-CONDITIONING IN SMALL PASSENGER CABIN USING SOLID WORKS
}

\author{
SHAMIM IBRAHIM ${ }^{1} \&$ R. C. MEHTA ${ }^{2}$ \\ ${ }^{1}$ Research Scholar, Department of Mechanical Engineering, Noorul Islam Centre for Higher Education, \\ Kumaracoil, Thuckaly, Tamil Nadu, India \\ ${ }^{2}$ Dean, Faculty of Aeronautical and Space Technology, Noorul Islam Centre for Higher Education,
} Kumaracoil, Thuckaly, Tamil Nadu, India

\begin{abstract}
As technology advances AC system is also adhering to major advancements. In general, automobile airconditioning systems are designed to provide comfort for the driver and the passengers during a journey. The conventional electrical-driven compression systems are widely used in almost all of the automobiles today. The objective of the research is to develop an air depression design inside the top surfaces of the rear cabin. The optimal flow of air inside the cabin increases the thermal comfort of the vehicle. The proposed cabin depression design inside the rear top surfaces is analyzed under thermal variation and air-flow circulation inside the cabin. The proposed design motivates with the designing phase of the new intelligent cabin for increasing the air-flow inside the cabin surfaces. The designing of the cabin is undergoing by Solid Works software and analyzed under real-time constraints. From the evaluation results, it is clear that the proposed cabin design has efficient air flow and air conditioning than conventional car cabin respectively.

KEYWORDS: Air-Conditioning, Air Flow, Car Cabin, Solid Works, Designing \& Compression Systems
\end{abstract}

Received: Jul 10, 2018; Accepted: Aug 01, 2018; Published: Aug 14, 2018; Paper Id: IJMPERDAUG2018112

\section{INTRODUCTION}

Ventilation and air-conditioning have turned into a standard alternative on most vehicles, upgrading comfort and passenger safety. Current frameworks highlight incorporated cooling, warming, de-moistening, deicing, air separating, and climate control [1]. The impacts of changes in the climate of the car on the warm condition of the passenger were considered. Sen et al [2] explore the cabin pointing with a view to making sense of the base normal speed over the travelers at all vent positions [2]. Cabin pointing guarantees a considerable measure of air flow spans to the travelers and in addition each edge of the lodge over the wide climatic range. As a result, automobile air conditioning to comfort the driver and the passenger has become essential in luxury today [3]. Consequently, the automobile air conditioner has become the major energy consuming auxiliary system in a passenger car, decreasing the mileage and increasing the pollution. Ajay Giri et al [4] explored the air flow and temperature circulation in the cabin of a vehicle with various vent speeds considering an inlet vent in front and an outlet in the back of the vehicle. Pang, S. C et al [5] made a review study to evaluate the air-flow and cooling flow circuit in the vehicle cabin. Since an automobile air-conditioning system is tested for different speeds, an empirical equation for volumetric efficiency, as a function of speed and pressure ratio, is obtained by the curve fitting the experimental data [6]. 


\section{LITERATURE SURVEY}

Temperature dispersion improves with increment in the channel speed and general cabin temperature is diminished with giving vent in the cabin. In summer the climatic temperature in a few sections of India contacts $45^{\circ} \mathrm{C}$. In such condition, the temperature inside the car cabin can even surpass $50^{\circ} \mathrm{C}$ and it turns out to be to a great degree hard to work for the driver and passengers [7]. It may affect the driver's health as well as may cause accidents. It affects the economy as the transportation time increases. So there is a need of the cooling system to keep the temperature of the cabin in control. The car air-conditioner provides comfort to the occupant in a hot weather. Ling et al [16] present another reproduction device that uses an appropriate orthogonal decomposition (POD) strategy. The POD strategy is to anticipate the air temperature profile inside a car cabin as an option way to deal with the conventional CFD technique. The outcomes demonstrate the time expended for the investigation is lower than regular examination procedure [9]. The Conventional Air-Conditioning System (CAS) draws its capacity from the motor which expends more fuel, particularly amid the startup after a long sun dousing. Numerous specialists in various parts of the world have been attempting to build up an answer for vehicle ventilation and cooling utilizing the distinctive variation to the vehicle interior surfaces10]. Therefore the specific objective of this research work is to experimentally study the feasibility of designing an air flow efficient cabin to improve the air conditioning of the car. A. Grundstein et al [11] looks at cabin temperatures under variable climate conditions. This examination considers is to measure the impact of various encompassing air temperatures and solar powered radiation values on vehicle cabin temperatures [12]. The proposed design utilized to design and analysis of air conditioning in passenger vehicles under airflow analysis. A numerical model is made to foresee the vehicle cooling execution under consistent state conditions [13]. From the thermodynamic and psychometric investigation, it is clear that an adjustment in the relative moistness can promote the procedure of ventilation and cooling and consequently decrease thermal losses [14]. The air-conditioning is analyzed using CFD modeling for suitability to reduce the car cabin temperature is further analyzed by experimentation for result validation [15-17]. This research paper is organized in the following ways, the past literature survey for the research is elaborated in section 2, the proposed design for the investigation of air flow in the cabin surface is defined in section 3 and the experimentation and analysis results are elaborated in section 4. Finally, the conclusion of the research methodology is clearly defined in section 5 respectively.

\section{MODELING OF EFFICIENT AIR-CONDITIONING CAR CABIN}

The air flow inside the vehicle is directed to a small section due to the limited space of the car. Generally, the air flows from air conditioning vents will increase the air velocity and it will be blocked by the front seats and rear seats and formed recirculating flow patterns. This research can give a clear study to improve the flow of air in vehicle cabin and thereby increasing the air conditioning of the vehicle. This paper proposes an airflow depression which is optimal for the continuous airflow in front and rear side of the cabin. The methodology starts with a design procedure of cabin with an aerodynamic projection on the roof surface of the rear passenger side. These projections lead the airflow continuously circulated to the passenger seated on the rear side. The air flow of vehicle is analyzed at different pressure limits with solar radiation and the geometry model of the cabin is created by the Solid Works and analyzed under real-time constraints. From the theoretical and practical evaluation, the proposed cabin design can improve the efficiency of the air flow inside the cabin surfaces respectively. 


\subsection{Experimental Setup}

The proposed setup of the experiment is carried out in the following passenger vehicle with the following analyzing parameters given in the table 1 .

Table 1: Parameters for Analysis

\begin{tabular}{|c|l|l|c|c|}
\hline \multirow{2}{*}{ S. No } & \multicolumn{3}{|c|}{ Analyzing Parameters } \\
\cline { 2 - 4 } & \multicolumn{1}{|c|}{} & \multicolumn{1}{|c|}{ Inner Surface } & Outer Surface \\
\hline \multirow{2}{*}{1.} & \multirow{2}{*}{$\begin{array}{l}\text { Cabin } \\
\text { Dimension }\end{array}$} & Length $(\mathrm{m})$ & 1.03 & 1.13 \\
\cline { 3 - 5 } & & Width $\sim \mathrm{L} / 2(\mathrm{~m})$ & 0.76 & 0.56 \\
\cline { 2 - 4 } & Height $(\mathrm{m})$ & 1.15 & 1.21 \\
\hline 2. & Solar Intensity $\left(\mathrm{W} / \mathrm{m}^{2}\right)$ & $500-800$ & $500-800$ \\
\hline 3. & Temperature $\left({ }^{\circ} \mathrm{C}\right)$ & 16 to 25 & 30 to 38 \\
\hline 4. & Air Velocity $(\mathrm{m} / \mathrm{s})$ & 0.1 to 0.5 & 0.1 to 0.5 \\
\hline 5. & Air Vents & 4 (inlet) & 2 (outlet) \\
\hline 6. & Air Pressure (bar) & 1 to 1.3 & 1 to 1.3 \\
\hline
\end{tabular}

\section{EXPERIMENTAL ANALYSIS AND RESULT DISCUSSION}

The proposed technique is implemented in the working platform of Ansys Fluent with the system specification.

Processor: Intel Core 2 Quad @ $2.5 \mathrm{GHz}$

RAM: 3GB

Operating system: Windows 7

Modeling Software: Solid Works

\subsection{Design of Air Flow Depression on Cabin Surfaces}

Air-conditioning in the vehicle is mainly determined by the orientation of air duct design such as the increase of air vents, shape and position of air vents in the vehicle cabin. All budgetary passenger vehicle factory fitted with four air vents in dashboard. However, the conditioning of passengers in front side is cooled/heated by the center mounted vents. But in the case of the rear passenger side, the vents mounted on the side of dashboards are utilized.

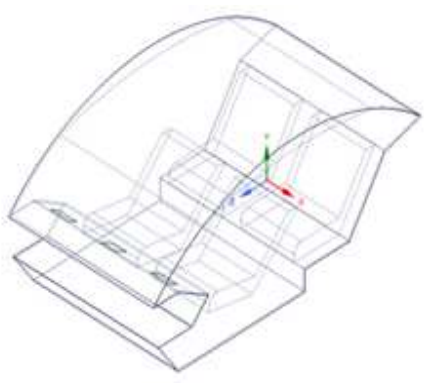

(a) Existing Model

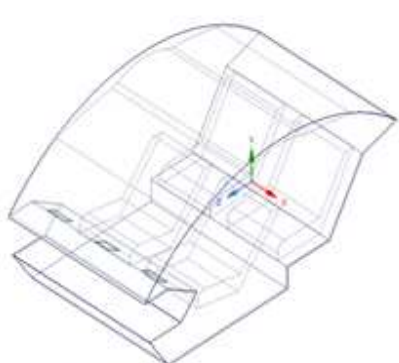

(b) Proposed Model

Figure 1: Modeling of Vehicle Cabin Surfaces

Commercial cars are come with a standard 2 outlet and 4 inlet air vents on the dashboard. Ordinarily, the inside air vents are focused to cool back travelers and the side air vents are for driver and codriver. When comes to luxury vehicles, each side is provided with air-vents. But in budgetary vehicles, the air conditioning is a concerning factor. To optimize these factors, the proposed research motivates to develop and design an efficient air depression shape upside 
to the rear passenger to make the air flow directed from the center air vent console. Thus the air conditioning becomes more efficient for the rear passengers. The following figure defines the cabin surfaces are modified from the vehicle conventionally air conditioned. The modification on the cabin surface is classified in the given figure 1 section respectively.

\subsubsection{Free Convection}

Free convection originates from a thermal instability. A different type of instabilities may also arise such as hydrodynamic instabilities that relate to a transition between a laminar to a turbulent flow. Due to the viscosity of the fluid (air), a very thin layer doesn't move relative to the wall. The temperature decreases from the value of the wall $T_{w}$ to room temperature $T_{\infty}$ in the same distance from the wall. The heat transfer by convection mechanisms is derived from Newton's law of cooling in equation (1).

$$
Q=h \cdot A \cdot\left(T_{w}-T_{\infty}\right)
$$

Where, $Q$ is the rate of heat transferred between the exposed surface $A$ of the wall and the fluid $T_{w}$ is the temperature of the wall, $T_{\infty}$ is the temperature of the free stream of air, $h$ is the convection coefficient.

\subsubsection{Convection Coefficient Evaluation}

The occurrence of fluid flow is usually correlated with Rayleigh number, which is simply the product of the Grashof and Prandtl numbers. Grashof number for convection is given in the following equation.

$$
G r=\frac{L^{3} \cdot g \cdot \beta \cdot\left(T_{w}-T_{\infty}\right)}{v^{2}}
$$

Where, $L$ is the characteristic length of the surface in meter, $g$ is gravity in $m / s^{2}, \beta$ is the thermal expansion coefficient in $1 / K, v$ is the kinematic viscosity in $m^{2} / s, T_{w}$ is the outer surface temperature and $T_{\infty}$ is the inner surface temperature at ambient condition. Therefore, the film temperature of the surface can be evaluated from the following equation.

$$
T_{f}=\frac{T_{w}+T_{\infty}}{2}
$$

For ideal gases, $\beta=\frac{1}{T_{f}}$ while for liquids and non-ideal gases the expansion coefficient must be obtained from appropriate property tables. Prandtl number is the ratio of two molecular transport properties, the kinematic viscosity $v$ which affects the velocity profile and the thermal diffusivity $\alpha$, which affects the temperature profile and $k$ is the fluid thermal conductivity in $W / m K, C_{p}$ is the fluid specific heat in $J / K g K$. 


\subsubsection{Thermal Convection Inside the Cabin Surface}

From the constraints taken for the temperature of the air, the Rayleigh number can be calculated from the given equation.

$$
R_{a}=2.62 L^{3}
$$

Where, $R_{a}$ is the Rayleigh number, $C$ and $n$ are drag coefficients. Typically, $n=1 / 4$ for laminar flow and $n=1 / 3$ for turbulent flow. For turbulent flow, $R_{a}>10^{9}$, for laminar flow $R_{a}<10^{9}$. Thus the convection is considered separately from the sides as well as the other two horizontal surfaces (top and bottom). Then the Rayleigh number for the convection is calculated from the equation (4) respectively. Therefore, the Nusselt number is evaluated from the given equation as follows.

$$
\bar{N} u=\frac{\bar{h}_{\text {in } / o u t} \cdot L}{k}=C \cdot R_{a}^{n}
$$

Where $C$ is the drag coefficient of air at 1.05 and $R_{a}^{n}$ be the Rayleigh number for laminar flow at $n=1 / 3$. Using Newton's law of cooling, heat transferred to the outside cabin temperature to the room cabin temperature can be calculated from the given equation (6).

$$
Q=\bar{h}_{i n} \cdot A \cdot\left(T_{w}-T_{\infty}\right)
$$

\subsubsection{Heat Convection outside the Cabin Surface}

Air properties are evaluated in thermal data at film temperature, $T_{f}=334 \mathrm{~K}$. For the wall temperature of $334 \mathrm{~K}$, the properties of the cabin film temperature at $334 \mathrm{~K}$ are evaluated form the data table and the Rayleigh number for the wall temperature can be calculated from equation (4) and achieved at $R_{a}=3.780$, and follows transition to turbulent flow occurs on the wall. The convection coefficient of the wall can be evaluated from the following equations as below.

$$
\bar{N} u=\left\{0.825+\frac{0.387 \cdot R_{a}{ }^{1 / 6}}{\left[1+(0.492 / \operatorname{Pr})^{9 / 16}\right]^{8 / 27}}\right\}^{2}
$$

Table 2: Experimental Analysis for Temperature Variation in Existing Vehicle Cabin

\begin{tabular}{|c|c|c|c|c|c|c|c|c|}
\hline$P($ Pascal $)$ & $V(m / s)$ & $T_{w}(K)$ & $T_{\infty}(K)$ & $R_{e}$ & $\operatorname{Pr}$ & $G r$ & $\bar{h}_{i n}$ & $Q\left(W / m^{2} K\right)$ \\
\hline \multirow{5}{*}{$1.2 \mathrm{e}+5$} & 0.1 & 319 & 300 & 1.30 & 0.69 & $3.07 \mathrm{e} 5$ & 0.0513 & 0.722 \\
\cline { 2 - 9 } & 0.2 & 319 & 298 & 1.30 & 0.69 & $3.55 \mathrm{e} 5$ & 0.0502 & 0.781 \\
\cline { 2 - 9 } & 0.3 & 319 & 295 & 1.30 & 0.69 & $4.26 \mathrm{e} 5$ & 0.0490 & 0.871 \\
\cline { 2 - 9 } & 0.4 & 319 & 293 & 1.30 & 0.69 & $5.32 \mathrm{e} 5$ & 0.0454 & 0.874 \\
\cline { 2 - 9 } & 0.5 & 319 & 290 & 1.30 & 0.69 & $6.27 \mathrm{e} 5$ & 0.0442 & 0.949 \\
\hline
\end{tabular}

In table 2 , the temperature variation inside the cabin is experimented by the mathematical model derived in the experimentation. The temperature of the cabin surface evaluated based on the air pressure, velocity and temperature acting on the inner and outer surface of the vehicle cabin. 
Table 3: Experimental Analysis for Temperature Variation in Proposed Cabin

\begin{tabular}{|c|c|c|c|c|c|c|c|c|}
\hline$P($ Pascal $)$ & $V(m / s)$ & $T_{w}(K)$ & $T_{\infty}(K)$ & $R_{e}$ & $\operatorname{Pr}$ & $G r$ & $\bar{h}_{i n}$ & $Q\left(W / m^{2} K\right)$ \\
\hline \multirow{5}{*}{$1.2 \mathrm{e}+5$} & 0.1 & 319 & 315 & 1.30 & 0.69 & $5.874 \mathrm{e} 6$ & 0.0534 & 0.1582 \\
\cline { 2 - 9 } & 0.2 & 319 & 312 & 1.30 & 0.69 & $1.479 \mathrm{e} 6$ & 0.0532 & 0.2759 \\
\cline { 2 - 9 } & 0.3 & 319 & 310 & 1.30 & 0.69 & $13.41 \mathrm{e} 6$ & 0.0530 & 0.3534 \\
\cline { 2 - 9 } & 0.4 & 319 & 305 & 1.30 & 0.69 & $21.32 \mathrm{e} 6$ & 0.0526 & 0.5456 \\
\cline { 2 - 9 } & 0.5 & 319 & 300 & 1.30 & 0.69 & $30.73 \mathrm{e} 6$ & 0.0513 & 0.7222 \\
\hline
\end{tabular}

In Table 3, the experimental analysis is carried out in the mathematical model derived in the experimentation section. The analysis of cabin temperature is measured by the air flow pressure, velocity, and temperature inside and outside of the vehicle cabin. Thus the temperature inside the cabin at various wall temperature and constant room temperature is analyzed.

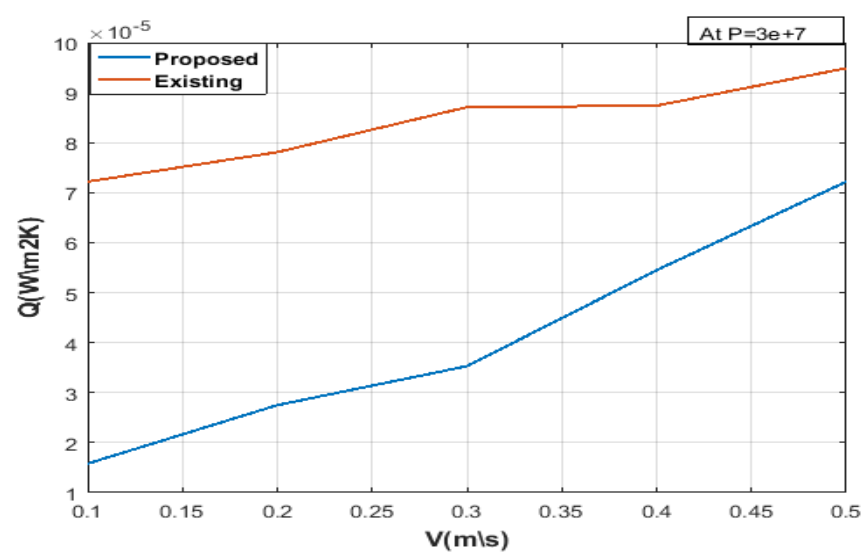

Figure 2: Performance Comparison of Cabin Surfaces

In figure 2, the performance of temperature and air flow in the cabin surfaces are analyzed for the proposed cabin surface. The pressure of air induced in the vehicle cabin is in the constant range of 1.2e+5 Pascal respectively. During the evaluation, the temperature inside the cabin surfaces decreases when the flow of air circulated inside the cabin surfaces increases. Ultimately, the surface temperature of the proposed cabin design has optimal air conditioning than the existing design. Hence, the results clearly define the proposed cabin design can efficiently provide air conditioning in small conventional passenger vehicles respectively.

\section{CONCLUSIONS}

Air conditioning in vehicles are largely utilized world widely, the influence of effective thermal comfort and air flow inside the vehicle cabin is one the research criteria throughout these years. In this research paper, effective air conditioning inside rear passenger area is analyzed. The analysis is carried out on small-sized passenger vehicle with air vents at the front side by designing the effective depression design to the rear side of the cabin can increase the thermal comfort of the vehicle. The work is extended by air depression design on the rear top surface of a conventional car by the solid works software and analyzed in Ansys fluent software at different temperature zones and air flows. The proposed design is modeled in solid work software and different thermal comfort and airflow inside the cabin is evaluated. Ultimately, the temperature coefficient and airflow circulation can be further researched and compared with the simulation environment for better efficiencies respectively. Ultimately from the research conclusion the proposed cabin design can obtain better efficiency in air conditioning in passenger car respectively. 


\section{REFERENCES}

1. Cullimore, Brent A., and Terry J. Hendricks. Design and transient simulation of vehicle air conditioning systems. No. 200101-1692. SAE Technical Paper, 2001.

2. Sen, Somnath, and Mayur Selokar. "Numerical simulation and validation of cabin aiming and cool-down of a passenger car”, SAE International Journal of Passenger Cars-Mechanical Systems, Vol. 9, No. 1, pp: 52-61, 2016.

3. Fayazbakhsh, Mohammad Ali, and Majid Bahrami. Comprehensive modeling of vehicle air conditioning loads using heat balance method. No. 2013-01-1507. SAE Technical Paper, 2013.

4. Ajay Giri et al "Investigation of Air Circulation and Temperature Distribution in Car Compartment" International Advanced Research Journal in Science, Engineering and Technology, Vol. 4, No. 3, 2017.

5. Pang, S. C., et al. “A review on air flow and coolant flow circuit in vehicle's cooling system”, International Journal of Heat and Mass Transfer, Vol. 55, No. 23, pp: 6295-6306, 2012.

6. Danasabe, M. A. H. M. O. O. D., \& Elias, N. (2016). Postpartum Depression Among Hausa Ethnic Women In Abubakar Tafawa Balewa University Teaching Hospital, North East Nigeria. IMPACT: International Journal Of Research In Humanities, Arts And Literature (IMPACT: IJRHAL), 4(3), 55-64.

7. He, Z. C., et al. "Coupled analysis of $3 D$ structural-acoustic problems using the edge-based smoothed finite element method/finite element method." Finite Elements in Analysis and Design 46.12 (2010): 1114-1121.

8. Sanaye, S., and M. Dehghandokht. "Thermal modeling for predication of automobile cabin air temperature." International Journal of Automotive Engineering 1.3 (2011): 152-164.

9. Ling, Jiazhen, et al. "A new computational tool for automotive cabin air temperature simulation”, SAE International Journal of Passenger Cars-Mechanical Systems, Vol. 6, No. 1, pp: 841-846, 2013.

10. Huang, Yanjun, et al. "An energy-saving set-point optimizer with a sliding mode controller for automotive airconditioning/refrigeration systems." Applied energy 188 (2017): 576-585.

11. Torregrosa-Jaime, Bárbara, et al. "Transient thermal model of a vehicle's cabin validated under variable ambient conditions." Applied Thermal Engineering 75 (2015): 45-53.

12. A. Grundstein, V. Meentemeyer, J. Dowd, "Maximum vehicle cabin temperatures under different meteorological conditions," International Journal of Biometeorology, Vol. 53, No. 3, pp: 255-261, 2009.

13. Sukumar, Naveen, et al. New Virtual Methodology for Analysis of Vehicle Cabin Using 1-D Elements. No. 2016-28-0240. SAE Technical Paper, 2016.

14. Rathee, I. N. D. U. (2014). Anxiety, depression and stress: a comparative study of school teachers working in residential and non-residential schools. Int J Res Human Arts Lit, 2(8), 1-6.

15. Bera, Tarun Kumar, et al. "Thermal modelling, simulation and experimental validation of heat accumulation in a framed glass cabin." Journal of Theoretical and Applied Mechanics 55.3 (2017): 911-922.

16. Marcos, David, et al. "The development and validation of a thermal model for the cabin of a vehicle." Applied Thermal Engineering 66.1-2 (2014): 646-656.

17. Singh, Samrendra, and Hesam Abbassi. "1D/3D transient HVAC thermal modelling of an off-highway machinery cabin using CFD-ANN hybrid method." Applied Thermal Engineering135 (2018): 406-417. 
18. Sathish, T. "Performance Measurement on Extracted Bio-Diesel from Waste Plastic", Journal of Applied Fluid Mechanics, Vol. 10, pp. 41-50, 2017.

19. Sathish, T. "Heat Transfer Analysis Of Nano-fluid Flow In A Converging Nozzle With Different Aspect Ratios", Journal of New Materials for Electrochemical Systems, Vol. 20, pp. 161-167, 2017. 